\title{
The short-term outcomes of hip arthrodesis in children and adolescents with end-stage hip disease
}

\author{
Thato A Mniki, ${ }^{1 *}$ (D) Pieter H Maré, ${ }^{2}$ Leonard C Marais, ${ }^{3}$ David M Thompson ${ }^{1}$ \\ 1 Department of Orthopaedic Surgery, Grey's Hospital, School of Clinical Medicine, University of KwaZulu-Natal, South Africa \\ 2 Clinical Unit Paediatric Orthopaedics, Department of Orthopaedic Surgery, Grey's Hospital, School of Clinical Medicine, University of KwaZulu-Natal, \\ South Africa \\ ${ }^{3}$ Department of Orthopaedic Surgery, School of Clinical Medicine, University of KwaZulu-Natal, South Africa
}

${ }^{*}$ Corresponding author: t.mniki@yahoo.com

Citation: Mniki TA, Maré PH, Marais LC, Thompson DM. The short-term outcomes of hip arthrodesis in children and adolescents with end-stage hip disease. SA Orthop J 2021;20(4):219-225. http://dx.doi. org/10.17159/2309-8309/2021/ v20n4a5

Editor: Dr Greg Firth, University of the Witwatersrand, Johannesburg, South Africa

Received: September 2020

Accepted: January 2021

Published: November 2021

Copyright: @ 2021 Mniki TA. This is an open-access article distributed under the terms of the Creative Commons Attribution Licence, which permits unrestricted use, distribution and reproduction in any medium, provided the original author and source are credited.

Funding: No funding was received for this study.

Conflict of interest: The authors declare they have no conflicts of interest that are directly or indirectly related to this work.

\section{Abstract \\ Background}

The management of end-stage hip disease in children and adolescents is a challenging clinical problem. While total hip replacement (THR) offers the benefit of improved mobility, this is offset by the risk of multiple revisions. Hip arthrodesis remains a salvage option to relieve pain and restore function at the cost of hip movement. This study aimed to determine the short- to medium-term outcome of hip arthrodesis in paediatric and adolescent patients in a developing world setting.

\section{Methods}

All children and adolescents under the age of 18 years who underwent hip arthrodesis between 2010 and 2014 were included in the study. Measurements included diagnosis, preoperative deformity, fusion position, fusion rate and functional outcomes. Our surgery involved transarticular compression screw fixation and subtrochanteric osteotomy. Postoperative skeletal traction maintained optimal limb position for two weeks, after which spica cast immobilisation was used.

\section{Results}

Nineteen patients (11 female) had hip fusions at a mean age of 12 years (range 5-18). The mean follow-up period was 5 years (range 1-8). Most cases were due to end-stage TB arthritis (12/19; $63 \%)$. Other causes were septic arthritis $(3 / 19 ; 16 \%)$; neglected slipped capital femoral epiphysis $(1 / 19 ; 5 \%)$; post-traumatic avascular necrosis (1/19; $5 \%)$; and idiopathic chondrolysis $(2 / 19 ; 11 \%)$. Primary fusion was achieved in $68 \%(13 / 19)$ of cases. Six patients developed complications. Complications included adduction drift (3/19), failed fusion (3/19), screw malpositioning (1/19) and screw breakage (1/19). Eight reoperations were required in six patients. In two of these patients, one additional surgery had to be performed to achieve fusion or correct limb position. The mean fusion position was $31^{\circ}$ (range 20 to 50 ) flexion, $2^{\circ}$ (range 10 to -10 ) abduction, and $1^{\circ}$ (range 10 to -10 ) external rotation. Mean leg length discrepancy was $1.8 \mathrm{~cm}$ (range 0 to 4.5 ) of shortening. All except one patient reported relief of hip pain and satisfaction with the procedure.

\section{Conclusion}

While hip arthrodesis is a technically challenging procedure, high fusion rates and reliable pain relief may be expected in these patients. However, complications should be anticipated, and reoperation may be required to achieve fusion and an optimal limb position.

Level of evidence: Level 4

Keywords: end-stage hip arthritis, TB hip, hip arthrodesis, hip fusion, subtrochanteric osteotomy

\section{Introduction}

Management of paediatric and adolescent patients with end-stage hip arthritis remains challenging, and the trends in management have changed over time..$^{1,2}$ When hip preservation is not possible, the treatment options are either total hip replacement (THR) or hip arthrodesis. There is limited evidence to support the choice of one procedure over the other. ${ }^{3} \mathrm{Hip}$ arthrodesis is indicated as a salvage procedure for end-stage hip disease. .-7 $^{4}$ The goals of hip arthrodesis are a pain-free, stable hip joint that will improve function. ${ }^{1}$ The procedures' success was first reported in 1894. Since then, a variety of fusion techniques and modifications have been published, resulting in improved union rates with a decrease in complications. ${ }^{8}$

Total joint replacement in younger patients has been gaining popularity due to the advantage of retained hip mobility and potential for improved functional outcomes. However, the risk of multiple revisions due to the demand placed on the prosthesis is of significant concern. ${ }^{2,9-13}$ Furthermore, appropriate patient selection for THR is crucial. Septic arthritis is a frequent cause of end-stage hip disease in children and adolescents. Prosthetic joint infection due to reactivation of infection is an additional risk in these patients, making hip arthrodesis an attractive alternative..$^{14,15}$ 
Table I: Patient demographics

\begin{tabular}{|c|c|c|c|c|c|c|}
\hline Patient & $\begin{array}{c}\text { Sex } \\
\text { (Female/ Male) }\end{array}$ & $\begin{array}{l}\text { Hip affected } \\
\text { (Right/ Left) }\end{array}$ & $\begin{array}{c}\text { Age at fusion } \\
\text { (years) }\end{array}$ & Diagnosis & Presentation & $\begin{array}{c}\text { Preoperative } \\
\text { traction use }\end{array}$ \\
\hline 1 & $\mathrm{~F}$ & $\mathrm{R}$ & 14 & Chronic SCFE & Progressive painful stiff hip & No \\
\hline 2 & M & $\mathrm{R}$ & 14 & Idiopathic chondrolysis & Progressive hip pain & No \\
\hline 3 & $\mathrm{~F}$ & $\mathrm{~L}$ & 10 & $\mathrm{SAH}$ & Acute pain, non-ambulatory & Yes \\
\hline 4 & $\mathrm{~F}$ & $\mathrm{R}$ & 10 & Idiopathic chondrolysis & Progressive pain limp & No \\
\hline 5 & M & $\mathrm{L}$ & 16 & TB hip ${ }^{\mathrm{iii}}$ & Progressive pain limp & Yes \\
\hline 6 & $\mathrm{~F}$ & $\mathrm{~L}$ & 14 & TB hip & Progressive painful stiff hip & No \\
\hline 7 & $\mathrm{~F}$ & $\mathrm{~L}$ & 18 & TB hip & Progressive painful limp & No \\
\hline 8 & $\mathrm{~F}$ & $\mathrm{R}$ & 11 & TB hip & Progressive pain, limp, sinus & Yes \\
\hline 9 & M & $\mathrm{L}$ & 8 & $\mathrm{SAH}$ & Acute pain, non-ambulatory & Yes \\
\hline 10 & $\mathrm{~F}$ & $\mathrm{~L}$ & 5 & TB hip & Progressive hip pain & Yes \\
\hline 11 & $\mathrm{~F}$ & $\mathrm{~L}$ & 12 & TB hip & Progressive pain stiff - jog movement & No \\
\hline 12 & M & $\mathrm{R}$ & 6 & TB hip & Progressive painful limp & Yes \\
\hline 13 & M & $\mathrm{R}$ & 14 & TB hip & Progressive pain, limp ankylosis & No \\
\hline 14 & $\mathrm{~F}$ & $\mathrm{~L}$ & 9 & TB hip & Progressive pain, non-ambulatory & Yes \\
\hline 15 & M & $\mathrm{R}$ & 18 & TB hip & Hip pain, non-ambulatory & Yes \\
\hline 16 & $\mathrm{~F}$ & $\mathrm{~L}$ & 14 & AVN post-traumatic & Progressive hip pain & No \\
\hline 17 & $\mathrm{~F}$ & $\mathrm{R}$ & 12 & TB hip & Progressive hip pain & No \\
\hline 18 & M & $\mathrm{L}$ & 14 & TB hip & Progressive hip pain & Yes \\
\hline 19 & M & $\mathrm{R}$ & 15 & $\mathrm{SAH}$ & Progressive hip pain & No \\
\hline
\end{tabular}

i) slipped capital femoral capital epiphysis, ii) septic arthritis, iii) tuberculosis

Hip arthrodesis has performed relatively well in the pre-arthroplasty era, demonstrating good to excellent long-term functional outcomes. ${ }^{16-20}$ More recently, similar results have been reported. ${ }^{21,22}$ The occurrence of adjacent joint degenerative disease is a wellknown long-term complication of hip arthrodesis. Up to $21 \%$ of patients require fusion takedown and conversion to THR. ${ }^{18-19,23-27}$

In the developing world, young patients often present late with advanced disease, severe pain and functional impairment. Furthermore, the prevalence of infective causes like tuberculosis (TB) or septic arthritis is high. In these cases, an abductor-sparing hip arthrodesis may be a good option to relieve pain and improve function. There is limited data on the outcome of hip arthrodesis in children and adolescents, particularly from the Southern African region.

Our study aims to determine the short- to medium-term outcome of hip arthrodesis in paediatric and adolescent patients in a developing world clinical setting. Our objectives were to determine the cause of end-stage hip disease, to measure the fusion position, to document the complication rate and report the subjective functional outcome in a cohort of children who underwent hip arthrodesis.

\section{Materials and methods}

We completed a single-centre retrospective descriptive study of all children and adolescents, under the age of 18 years, who had a hip arthrodesis at our tertiary paediatric orthopaedic unit between 2010 and 2014. All patients 18 years and younger who underwent hip arthrodesis for end-stage hip disease and had follow-up for at least one year were included for analysis. All patients who had a hip arthrodesis after the age of 18 years and patients with active infection of the hip were excluded.

\section{Patient selection}

Patients were considered eligible for arthrodesis following failure of non-operative management for unilateral end-stage hip arthritis. Failed non-operative treatment was defined as inability to achieve or maintain functional position of the hip or inability to control pain sufficiently to allow functional activities of daily living. Prior to the procedure, active infection was excluded through clinical examination, as well as imaging and laboratory investigations.

\section{Surgical technique}

An anterior approach (extended Smith-Peterson) was used to access the hip joint. This was followed by an anterior hip dislocation and acetabular exposure. Mechanical reamers designed for hip resurfacing were used to remove the remaining articular surface of the acetabulum and femoral head. Once bleeding cancellous bone surfaces were obtained, appropriately sized transarticular cannulated compression screws were inserted under fluoroscopic control in the position of maximal bone contact. A combination of autogenic and allogenic bone graft was used in certain cases with insufficient femoral bone stock. An additional subtrochanteric osteotomy was performed without supplemental fixation. The subtrochanteric osteotomy achieved two goals: first, the strain of the lower limb on the fusion site was removed. Secondly, because optimal bone contact was prioritised at the fusion site, the limb could be placed in the ideal functional position through the osteotomy site $\left(15-40^{\circ}\right.$ flexion, $0-10^{\circ}$ abduction and $0-10^{\circ}$ external rotation). . $^{1,6-7,24,28}$

During the immediate postoperative period, patients were placed in skeletal traction for a period of two weeks. This facilitated soft tissue healing and wound review, while maintaining the optimal alignment, and allowed for some initial soft callus formation. Subsequently a hip spica was applied under general anaesthesia and fluoroscopic 
Table II: Outcome measures

\begin{tabular}{lcc}
$\begin{array}{l}\text { Variable } \\
\text { Hip position }\end{array}$ & $\begin{array}{c}\text { Immediate } \\
\text { postoperative }\end{array}$ & $\begin{array}{c}\text { Final } \\
\text { follow-up }\end{array}$ \\
\hline Flexion (degrees) & $43(30$ to 50$)$ & $31(20$ to 50$)$ \\
\hline Abduction (degrees) & $8(15$ to -10$)$ & $2(10$ to -10$)$ \\
\hline External rotation (degrees) & $3(10$ to -10$)$ & $1(10$ to -10$)$ \\
\hline Leg lengths & & \\
\hline Shortening $(\mathrm{cm})$ & $1.6(1$ to 2.5$)$ & $1.8(0$ to 4.5$)$ \\
\hline Union & & $13(68 \%)$ \\
\hline Definite union & - & $3(16 \%)$ \\
\hline Probable inion & - & $3(16 \%)$ \\
\hline Non-union & - & \\
\hline
\end{tabular}

i) mean (range), ii) n (\%)

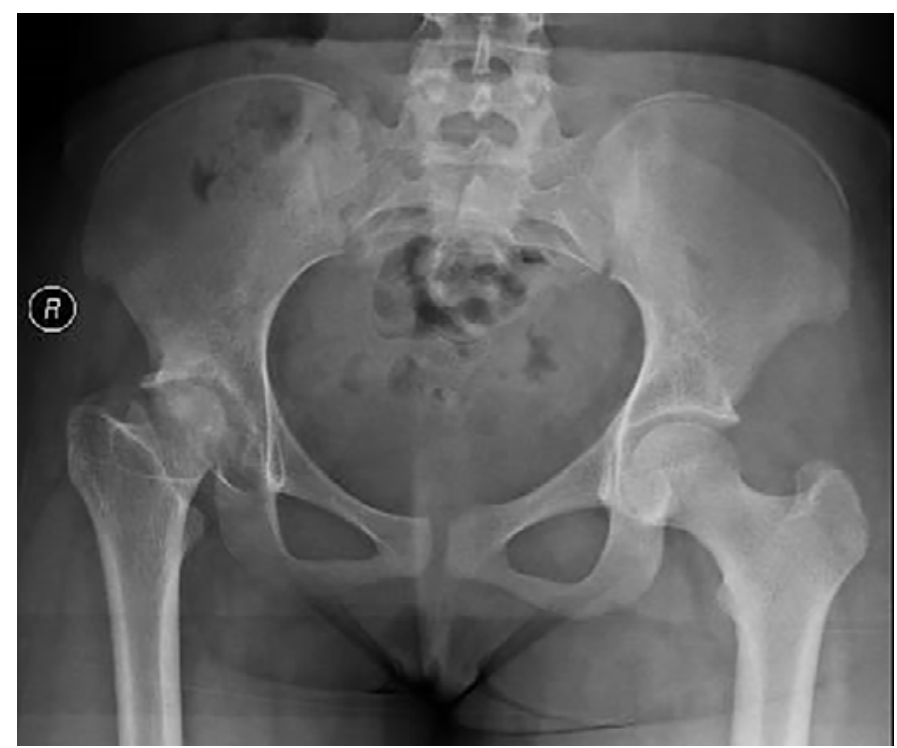

Figure 1. AP radiograph of the pelvis of a 15-year-old girl presenting with a 'mortar and pestle' type tuberculosis of the right hip. Features of secondary degenerative joint changes are evident (decreased joint space and osteophyte formation superolaterally, with subchondral sclerosis of the acetabulum and femoral head, and joint irregularity). guidance to maintain the desired limb position for a further eight to ten weeks. Patients were allowed to mobilise partial weightbearing with crutches, as pain allowed. A standardised follow-up schedule was maintained involving clinical and radiological review at two weeks, six weeks and three months, three months, six months and yearly, thereafter. The spica was removed at ten to 12 weeks postoperatively and union of the subtrochanteric osteotomy was confirmed clinically and radiologically.

\section{Data collection}

Demographic and clinical data were collected and analysed. Data points included age, sex, initial diagnosis, side affected, preoperative position of the hip (degree of flexion, abduction, rotation) and leg length discrepancy. The leg length and alignment were assessed in the supine position with the pelvis squared. The amount of hip adduction/abduction can be measured as compared to the non-arthrodesed hip. With addition of the Thomas test, the amount of flexion was obtained. The true leg length discrepancy was measured while placing the limbs in identical positions. Outcome measurements included complications, reoperation, fusion rate, final fusion position and patient satisfaction. All secondary procedures were analysed to determine their indications and subsequent outcome. Clinical fusion was defined as no pain or movement at the hip on clinical examination. Radiological fusion was categorised as either definite fusion (trabecular lines crossing fusion site and clinically fused), probable fusion (no trabecular lines crossing, but no lucency around the screws and no change in position on serial X-rays and clinically fused) or failed fusion (lucent zone across fusion site, with lucency around screws and change in position on serial X-rays; along with movement or pain at the hip on ambulation or examination).

The final functional outcome was conducted in person or by telephonic interview. The components assessed included pain of the fused hip, ipsilateral knee joint, contralateral hip and the lumbar spine. Limitations in sitting and walking were also recorded including the use of assistive devices. An excellent functional outcome was defined as no associated pain and limitations in the activities of daily living (sitting and walking). A good functional outcome was defined as adjacent joint pain with some limitation in activities of daily living. Poor functional outcome was defined as pain of the fused hip with or without adjacent joint pain that was associated with functional limitation (e.g. use of assistive device or inability to sit for a prolonged period).

Statistical analysis was performed using jamovi version 1.2.18.0

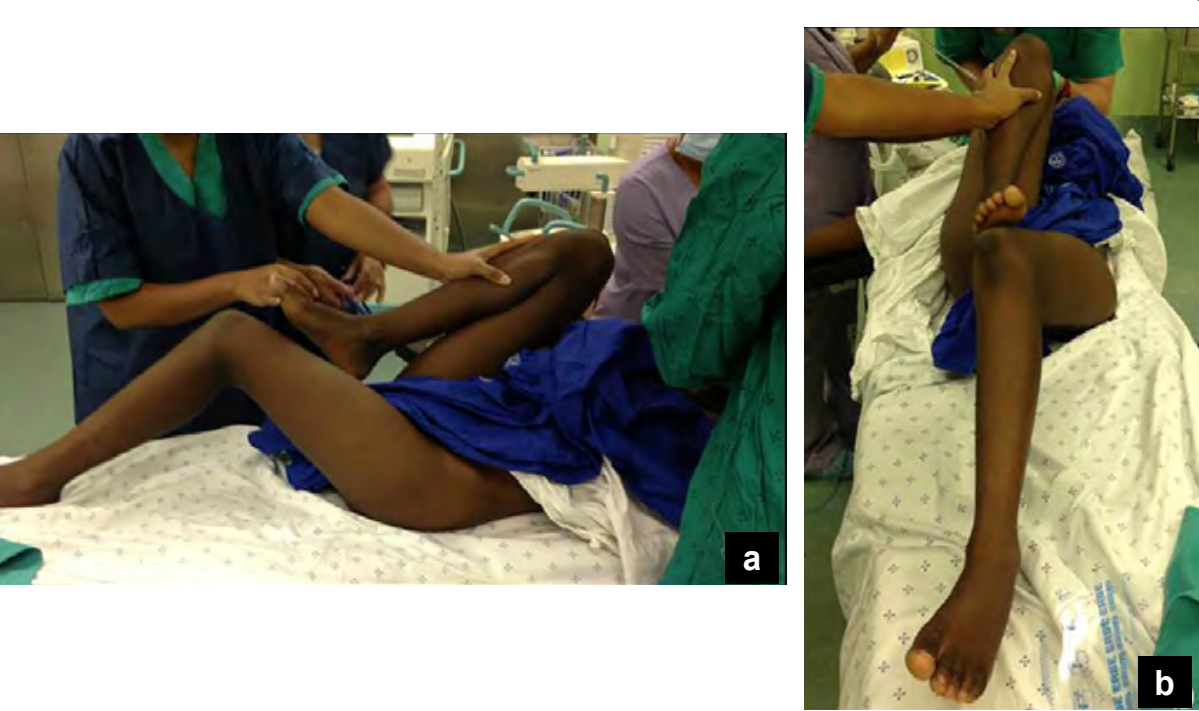

Figure 2. Preoperative clinical picture of a 14-year-old boy demonstrating a) fixed flexion deformity; and b) adduction contracture of the left hip open-source software. ${ }^{29}$ Continuous variables were reported as means with ranges, and categorical variables as number and percentages. Differences in continuous variables were compared with the use of the unpaired t-test or the Mann-Whitney $U$ test (depending on the distribution of the data). Categorical data was compared using the Fisher's exact test (if any expected cell count was below 5) or the chi-squared test (if no cell count below 5). All tests were twosided and the level of significance was set at $p<0.05$. Binomial logistic regression analysis was used to determine odds ratios (ORs) and 95\% confidence intervals $(95 \% \mathrm{Cl})$.

\section{Results}

Nineteen patients (11 females) were included in the study from a total of 
Table III: Summary of patients with complications

\begin{tabular}{|c|c|c|c|c|c|c|}
\hline Patient & Sex & $\begin{array}{c}\text { Age } \\
\text { (years) }\end{array}$ & Aetiology & Complication & Intervention & $\begin{array}{l}\text { Time to reoperation } \\
\text { (months) }\end{array}$ \\
\hline 1 & Female & 14 & SCFE & Adduction deformity & Valgus derotation osteotomy & 45 \\
\hline 2 & Female & 10 & SA hip & Failed fusion & Revision surgery, bone graft and refixation & 10 \\
\hline 3 & Male & 8 & SA hip & Failed fusion with screw breakage & Revision surgery, bone graft and refixation & 24 \\
\hline \multirow[t]{2}{*}{4} & Female & 5 & TB hip & Screw malposition & Screw revision & 5 \\
\hline & & & & Adduction deformity & Valgus derotation osteotomy & 29 \\
\hline \multirow[t]{2}{*}{5} & Male & 6 & TB hip & Failed fusion & Revision surgery, bone graft and screw refixation & 2 \\
\hline & & & & Failed fusion with screw breakage & $\begin{array}{l}\text { Revision surgery and refixation with dynamic hip } \\
\text { screw }\end{array}$ & 51 \\
\hline 6 & Female & 9 & TB hip & Adduction deformity & Valgus derotation osteotomy & 29 \\
\hline
\end{tabular}

SCFE: slipped capital femoral capital epiphysis; SA: septic arthritis; TB: tuberculosis

22 patients who underwent hip arthrodesis (Table I). Two patients were lost to follow-up within the first year following surgery and subsequently excluded. One patient with active bacterial septic arthritis was also excluded. The mean age at surgery was 12 years (range 5-18).

The causes of end-stage hip disease were TB of the hip in $63 \%$ $(12 / 19)$ (Figure 1); septic arthritis in 16\% (3/19); 11\% (2/19) due to idiopathic chondrolysis; and the remaining two cases were due to post-traumatic avascular necrosis (5\%) and complicated slipped capital femoral epiphysis $(5 \%)$, respectively.

Progressive, chronic and debilitating hip pain was the presenting complaint in $84 \%(16 / 19)$ of patients. This pain was associated with variable degrees of hip stiffness and deformity. With regard to the mean fixed flexion deformity, the data available in 16 patients was $44^{\circ}$ (range 20-70). For the mean adduction contracture, the data available in 13 patients was $16^{\circ}$ (range 5-30) (Figure 2). For the true leg length discrepancy, the data available in six patients was a mean of $3 \mathrm{~cm}$ (range 2-5). Preoperative skeletal traction was used in $47 \%(9 / 19)$ in an effort to improve limb position.

Transarticular fixation comprised two half-threaded compression screws in 18 cases (Figure 3). A single screw was used in the remaining case. The intended limb position was maintained in a hip spica until clinical and radiological healing of the osteotomy site was evident at 10-12 weeks postoperatively. The mean limb positions obtained immediately out of hip spica were: $43.3^{\circ}$ flexion, $8.3^{\circ}$ abduction, $2.5^{\circ}$ external rotation with an apparent LLD of $1.6 \mathrm{~cm}$ (Table II).
The mean follow-up time was five years (range 1-8). Definite fusion was obtained in 68\% (13/19) of patients (Figure 4), probable fusion in $16 \%(3 / 19)$ and the remaining $16 \%(3 / 19)$ developed a failed fusion after the initial fusion procedure (Figure 5).

The complication rate was $32 \%(6 / 19)$. The complications (Table III) included flexion and adduction drift (3/19), failed fusion (3/19), screw malpositioning (1/19) and screw breakage $(1 / 19)$. There were no non-unions of the subtrochanteric femoral osteotomies. Eight reoperations were required in six patients. In two of these patients, one additional surgery had to be performed in each patient to achieve fusion or correct limb position. Reoperations included valgus and extension osteotomies (3/8) for flexion and adduction drift; debridement and autologous bone grafting (3/8) for failed fusion; screw reposition (1/8) for screw malposition; and lastly revision surgery with plate osteosynthesis $(1 / 8)$ for failed fusion with screw breakage.

Subgroup analysis revealed that the quality of fusion was associated with the need for reoperation $(p=0.003)$. Five out of six patients that developed complications and subsequently underwent reoperation were either classified as probable fusion $(2 / 5)$ or as a failed fusion (3/5).

At final follow-up, hip fusion was achieved in all patients $(19 / 19)$. The mean hip position at last follow-up was $31^{\circ}$ flexion (range $20-50$ ), $2^{\circ}$ abduction (range $10^{\circ}$ abduction to $10^{\circ}$ adduction) and $1^{\circ}$ external rotation (range $10^{\circ}$ internal rotation to $10^{\circ}$ external rotation. The mean apparent LLD was $1.8 \mathrm{~cm}$ (range $0-4.5$ ) (Table II).

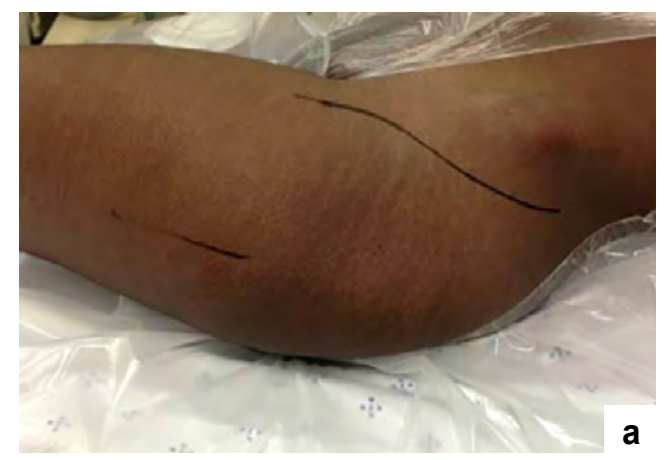

Figure 3. Perioperative images a) demonstrating patient positioning and skin marking for the planned incisions - the extended Smith-Petersen approach to the hip and straight lateral incision for the subtrochanteric osteotomy; b) the superficial dissection of the extended Smith-Petersen approach, with care to be taken in identifying and protecting the lateral femoral cutaneous (LFC) nerve; c) intraoperative AP fluoroscopic image confirming the appropriate screw length and placement, transarticular compression and subsequent subtrochanteric osteotomy; d) postoperative transtibial skeletal traction to allow initial soft tissue healing and to position limb in an optimal alignment
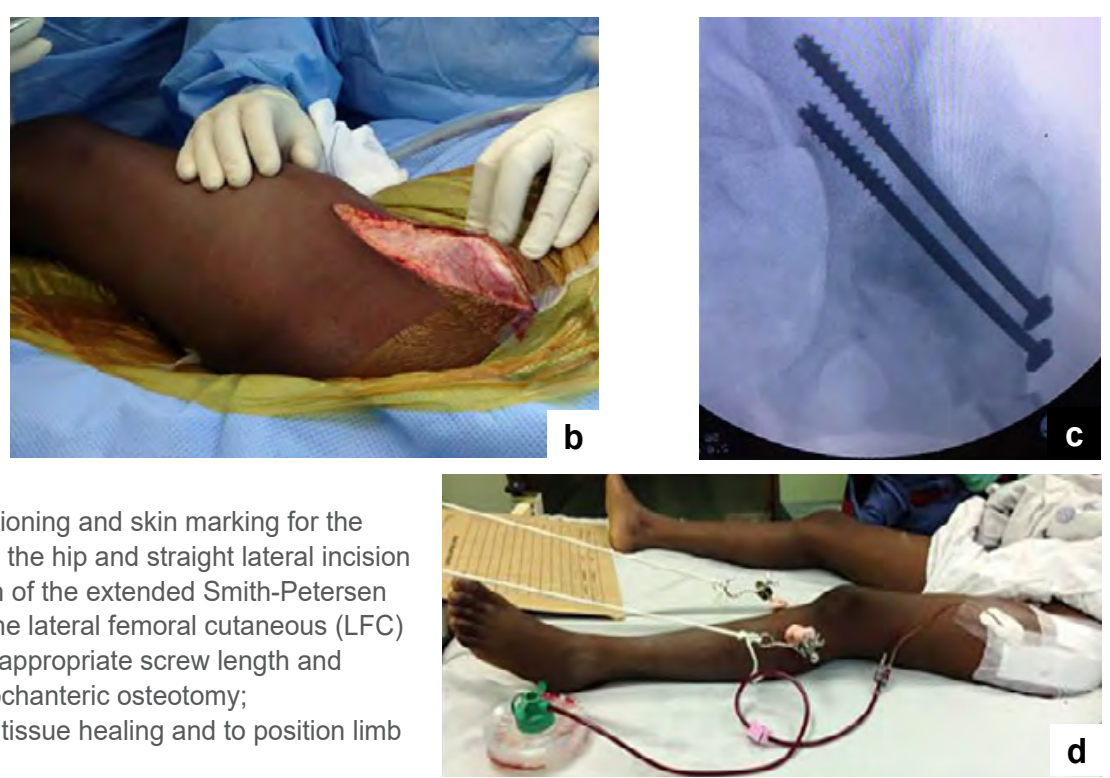

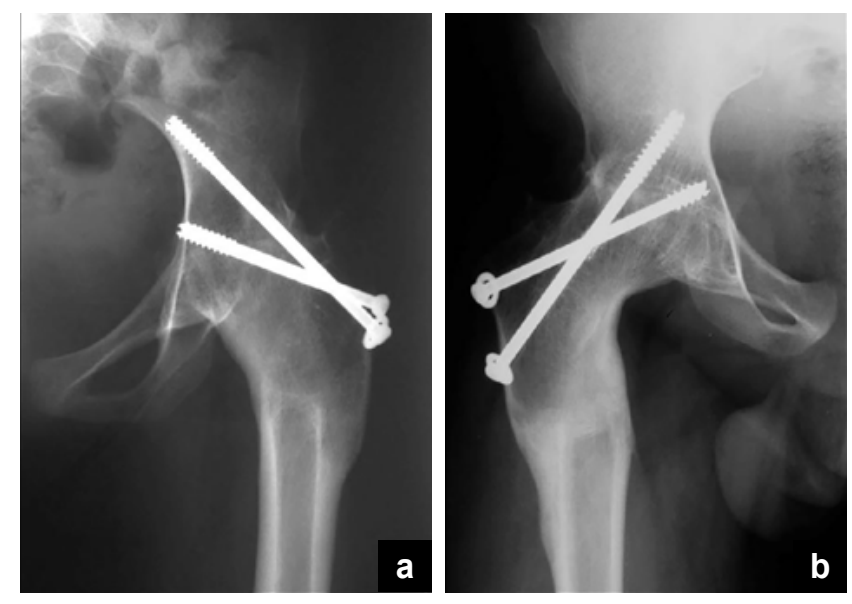

Figure 4. Postoperative AP radiographs a) of the left hip of a 14-year-old girl and b) of the right hip of a 14-year-old boy demonstrating definite fusion. The trabecular crossing sign is evident with no lucency around the screws.

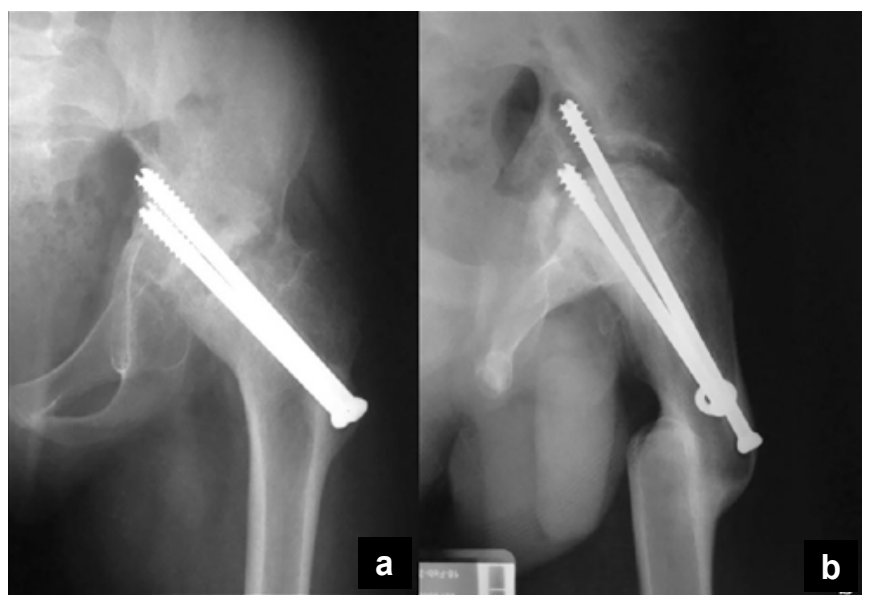

Figure 5. Postoperative AP radiographs a) demonstrating probable fusion, evident with a clear lucent zone at the fusion site; however, no lucency around the screws and clinically pain-free; and b) failed fusion, evident with fusion site lucency, screw halos and pain with weight bearing

All but one patient was free of hip pain at final follow-up. This patient experienced pain of the fused hip with long distance walking and when sitting for more than an hour. The same patient also reported ipsilateral knee and lumbar pain. A contributing factor to the symptoms may have been the leg length discrepancy of $3 \mathrm{~cm}$. The clinical outcomes were reported to be excellent in 16 patients and good in three patients. In the three patients with good results, the average apparent leg length discrepancy was $3.5 \mathrm{~cm}$ (range 3-4). This was managed with a shoe raise. No lengthening procedures or epiphysiodesis were performed.

We found increased odds for complications (odds ratio [OR] 1.5, $95 \% \mathrm{Cl} 1.1$ to $2.3, \mathrm{p}=0.028$ ) and the need for reoperation (OR $2.07,95 \% \mathrm{Cl} 1.1$ to $3.9, \mathrm{p}=0.022$ ) in patients of younger age. We were unable to demonstrate an association between the cause of end-stage hip disease and the development of complications $(p=0.322)$ or the need for reoperation $(p=0.240)$.

\section{Discussion}

The management of children and adolescents with end-stage hip disease remains a major challenge for orthopaedic surgeons. There is limited data available regarding the outcomes of hip arthrodesis in the developing world where patients often present late with more advanced disease and where infectious causes are common. ${ }^{4,7,30}$ Our study aimed to determine the short- to mediumterm outcome of hip arthrodesis in children and adolescents in a developing world clinical setting.

Hip arthrodesis remains a treatment option in children and adolescents presenting with unilateral end-stage hip disease with contraindications for joint preservation and replacement surgery. 1,4-7,22 Post-infective and post-traumatic hip arthrosis have been identified as the leading indications for hip arthrodesis. Postinfective causes account for up to $75 \%$, and trauma for up to $47 \%$ of cases. ${ }^{18,22-23,30}$ In keeping with these findings, $79 \%$ of our cases were the result of previous TB or septic arthritis. Two cases were due to idiopathic chondrolysis, and the remaining two cases were due to avascular necrosis following a neck of femur fracture, and chondrolysis following a slipped capital femoral epiphysis.

The indications for hip arthrodesis are debilitating hip pain and deformity due to end-stage hip disease when conservative management fails. The goal of hip arthrodesis is to obtain a painfree hip in a functional position. 1,6-7,31-33 In our series, 16 of the patients presented with debilitating pain that was associated with hip deformity (fixed flexion deformity, adduction contracture and leg length discrepancy).

The ideal functional fusion position is still an area of debate with conflicting recommendations. ${ }^{1,4-8}$ The currentrecommended position of the limb is $15-40^{\circ}$ of flexion, $0-10^{\circ}$ of abduction or adduction, and $0-10^{\circ}$ external rotation. ${ }^{1}$ In our series, the final fusion position achieved was in keeping with these recommendations, with $31^{\circ}$ flexion, $2^{\circ}$ abduction and $1^{\circ}$ of external rotation. lobst and Stanitski showed a greater degree of hip flexion (average $30^{\circ}$ ) was important in achieving a rhythmic gait and to facilitate sitting. ${ }^{5}$ On the other hand, Karol et al. noted a better gait pattern with a lesser degree of flexion of between $20^{\circ}$ and $25^{\circ}{ }^{26}$ Benaroch et al. demonstrated that slight abduction was necessary to compensate for the progressive adduction drift. ${ }^{24}$ However, Duncan et al. showed that any amount of abduction was associated with later knee varus deformity and instability and recommended neutral abduction-adduction. ${ }^{34}$ There appears to be consensus that internal rotation should be avoided to prevent interference with the opposite limb during walking. ${ }^{1}$ The mean leg length discrepancy in our patient group was $1.8 \mathrm{~cm}$. Symptomatic leg length discrepancy above $2 \mathrm{~cm}$ was treated with a shoe raise. Leg length discrepancy above $4 \mathrm{~cm}$ may require a staged femoral lengthening but was not required in any of our cases. ${ }^{1}$

Multiple surgical techniques are described in the literature. . $14-8,27,32-38$ The options include internal fixation with transarticular screws (e.g., cannulated compressing screws or dynamic hip screw system) or extra-articular fixation (e.g., cobra plate, low-contact dynamic compression plate). In the transarticular technique with compression screw, the use of a supplementation external fixation (e.g., AO modular Ex-Fix) is also described. ${ }^{28}$ Cobra plates were designed to address high rates of pseudarthrosis seen with transarticular techniques by providing a rigid internal fixation. These plates, however, damage the abductor mechanism, making later conversion to a THR challenging. ${ }^{37,38}$ The use of external fixators is frequently complicated by pin-track infections and knee stiffness. ${ }^{28,36}$ The procedure we preferred for hip arthrodesis has the following potential advantages: transarticular compression, sparing of the abductor muscles, and preservation of both bone stock and the vascular supply of femoral neck and head. The disadvantages include the prolonged hospital stay and cumbersome spica cast immobilisation. The potential benefits and drawbacks of performing a subtrochanteric osteotomy also need to be considered. Subtrochanteric osteotomy potentially increases the chances of union of the arthrodesis by decreasing the length of the lever arm and the resulting strain at the fusion site. Furthermore, as the hip is positioned in the optimal position to achieve union, 
the alignment of the limb can be adjusted at the subtrochanteric osteotomy site. However, THR following a previous proximal femoral osteotomy can be technically challenging with increased complication and revision rates compared to a primary total hip arthroplasty. ${ }^{39,40}$

While we achieved fusion in all cases, reoperations were required in $32 \%(6 / 19)$. We found that a younger age at surgery was associated with increased odds of reoperation (OR 2.07, 95\% $\mathrm{Cl} 1.1-3.9, p=0.022)$. Reoperations were required to either obtain fusion, or to maintain a functional position due to adduction and flexion drift. Fusion quality was also associated with reoperation $(p=0.003)$. All three failed fusions required reoperation to relieve pain and improve poor hip position. Two out of three patients that were categorised as 'probable fusion' also required reoperation, both due to adduction drift which was likely the result of incomplete fusion.

Brien et al., in their study of 16 patients fused with an anterior compression plate, demonstrated a $31 \%$ reoperation rate for fusion. ${ }^{33}$ However, Wagner and Wagner had a reoperation rate for fusion of $8 \%$ with the use of the cobra plate. ${ }^{37}$ In a series involving 17 patients fused with cobra plates, Mahran and Omar also demonstrated a high fusion rate with a $6 \%$ reoperation rate. ${ }^{22}$ Hoekman et al. augmented the transarticular compression with an anterior plate and showed a $94 \%$ fusion rate. ${ }^{21}$ While there are no comparative studies to show the superiority of one surgical technique over the other, the use of an anteriorly placed plate to supplement transarticular fixation may improve fusion rates. ${ }^{1,21}$

Good to excellent short-term subjective functional outcome was achieved in $95 \%$ of our patients, with one patient reporting symptoms of adjacent joint pain. This is comparable to other studies on the functional outcome after hip arthrodesis. Schafroth et al. evaluated the long-term outcome of 30 patients that underwent hip arthrodesis and showed that when the optimal limb alignment is achieved, complaints relating to the adjacent joints is minimal and acceptable quality of life is attainable. ${ }^{27}$ Hoekman et al. has demonstrated a high satisfaction rate in his 35-patient cohort and reported a good to a very good quality of life. ${ }^{21}$

After skeletal maturity, the management of end-stage hip disease is controversial, with some authors advocating for THR over hip fusion. ${ }^{3}$ THR has clear short-term advantages but uncertain longterm outcomes. Takenaga et al., in a ten-year follow-up study looking at patients 50 years and younger, reported a $15 \%$ revision rate. ${ }^{11}$ Furthermore it has been shown that further revisions can be expected in this group of patients (up to $30 \%$ ) with shorter implant survival times. ${ }^{10}$ Hip arthrodesis therefore remains a viable option in this high-demand patient group due to the concerns of implant loosening and the risk of multiple revisions. ${ }^{1,6}$ While hip arthrodesis restores function and relieves pain in end-stage hip disease, it is frequently complicated by adjacent joint degeneration in the long term. ${ }^{27}$ Later conversion of the fused hip to total hip arthroplasty may be considered to halt these processes and increase function, with improved quality of life. ${ }^{41}$ However, complications are relatively common in comparison to primary THA, occurring in up to $13 \%$ of cases, and the ten-year survival rate of the procedure varies from $74-96 \% .{ }^{42}$

There are several limitations to this study. As the study was retrospective, not all the preoperative measurements were documented in the medical records. The data regarding the disease course and the time from initial diagnosis to arthrodesis was also not available. Despite this limitation, these patients all met the indication for hip arthrodesis: a painful hip in a poor position, with end-stage hip disease that has failed non-operative management. The study was also subject to attrition bias with two patients being lost to follow-up. The small sample size is due to the relative rarity of end-stage hip disease in children and adolescents.
We found no obvious explanation for the finding that there is an association between younger age and increased complications and need for reoperation. This may also, possibly, be a function of the small sample size. Despite the small sample size, the study was sufficiently powered to detect an association between age and the odds of reoperation (post hoc power analysis $=98 \%$ power). This is a short-term outcome study on a young group of patients that underwent hip arthrodesis. Long-term complications include flexion and adduction drift and degenerative disease of other joints (ipsilateral knee, opposite hip and lumbar spine). Long-term follow-up is required to accurately determine the outcome of hip fusion in our patient cohort. As this is a single-centre study, further research is required to confirm external validity. Further study is also required to determine the association between underlying cause of hip disease and outcome, as well as the optimal surgical fusion technique.

\section{Conclusion}

Hip arthrodesis can provide reliable pain relief in selected children and adolescents with end-stage hip disease. The procedure is technically challenging with a significant complication and reoperation rate. Younger age may be associated with an increased risk of reoperation.

\section{Ethics statement}

Institutional Review Board ethical approval was obtained from the University of KwaZulu-Natal Biomedical Research Ethics Committee via an expedited application referenced: BE602/18 prior to commencement of the study.

The author/s declare that this submission is in accordance with the principles laid down by the Responsible Research Publication Position Statements as developed at the 2nd World Conference on Research Integrity in Singapore, 2010. The study was conducted with compliance to the South African National Research Ethics Guidelines (2015). All procedures were in accordance with the ethical standards of the responsible committee on human experimentation (institutional and national) and with the Helsinki Declaration of 1975, as revised in 2008. Informed written consent was not obtained for the study.

\section{Declaration}

The authors declare authorship of this article and that they have followed sound scientific research practice. This research is original and does not transgress plagiarism policies.

\section{Author contributions}

TAM: Data capture, manuscript preparation, manuscript revision

PHM: Manuscript review and revision

LCM: Manuscript review and revision

DMT: Study design, data capture, manuscript review

\section{ORCID}

Mniki TA https://orcid.org/0000-0003-1410-4508

Maré PH https://orcid.org/0000-0003-1599-7651

Marais LC 19 https://orcid.org/0000-0002-1120-8419

Thompson DM https://orcid.org/0000-0003-2607-3999

\section{References}

1. Bittersohl B, Zaps D, Bomar JD, Hosalkar HS. Hip arthrodesis in the pediatric population: where do we stand? Orthop Review. 2011;3(2):e13.

2. Swarup I, Lee Y, Chiu Y, et al. Implant survival and patient-reported outcomes after total hip arthroplasty in young patients. J Arthrop. 2018;33:2893-8.

3. Kelman MG, Studdert DM, Callaghan JJ, et al. The choice between total hip arthroplasty and arthrodesis in adolescent patients: A survey of orthopedic surgeons. J Arthroplasty. 2016;31:70-75

4. Clohisy JC, Beaulé PE, O'Malley A, et al. Hip disease in the young adult: current concepts of aetiology and surgical treatment. J Bone Joint Surg AM. 2008;90(10):2267-81.

5. lobst CA, Stanitski CL. Hip arthrodesis: Revisited. J Pediatr Orthop. 2001;21:130-4.

6. Stover MD, Beaule PE, Matta JM, et al. Hip arthrodesis: Procedure for the new millennium? Clin Orthop Relat Res. 2004;418:126-33.

7. Beaulé PE, Matta JM, Mast JW. Hip arthrodesis: current indications and techniques. J Am Acad Orthop Surg. 2002;10:249-58. 
8. Dabov G. Hip arthrodesis. In: Azar FM, Canale ST, Beaty JH, editors. Campbell's operative orthopaedics.13th ed. Elsevier; 2016, p. 337-44.

9. Tsukanaka M, Halvorsen V, Nordsletten L, et al. Implant survival and radiographic outcome of total hip replacement in patients less than 20 years old. Acta Orthop. 2016;87(5):479-84.

10. Lee PTH, Lakstein DL, Lozano B, et al. Mid- to long-term results of revision total hip arthroplasty in patients aged 50 years or younger. Bone Joint J. 2014;94-B:1047-51.

11. Takenaga RK, Callaghan JJ, Bedard NA, et al. Cementless total hip arthroplasty in patients fifty years of age or younger: A minimum ten-year follow-up. J Bone Joint Surg Am. 2012;94:2153-59

12. Clohisy JC, Oryhon JM, Seyler TM, et al. Function and fixation of total hip arthroplasty in patients 25 years of age or younger. Clin Orthop Relat Res. 2010;468:3207-13.

13. Toschia ME, Klassen RA, Bianco AJ. Total hip arthroplasty with cement in patients less than twenty years old. Long-term results. J Bone Joint Surg. 1996;78(7):995-1003.

14. Cherney DL, Amstutz HC. Total hip replacement in the previously septic hip. J Bone J Surg 1983;65(9):1256-65.

15. Balderston RA, Hiler WD, lannotti JP, et al. Treatment of the septic hip with total hip arthroplasty. Clin Orthop Relat Res. 1987 Aug;(221):231-7.

16. Fulkerson JP. Arthrodesis for disabling hip pain in children and adolescents. Clin Orthop Relat Res. 1977 Oct;(128):296-302.

17. Lipscomb PR, McCaslin FE Jr. Arthrodesis of the hip: Review of 371 cases. J Bone Joint Surg Am. 1961;43:923-50.

18. Sponseller PD, McBeath AA, Perpich M. Hip arthrodesis in young patients. A long-term follow-up study. J Bone Joint Surg Am. 1984;66:853-59.

19. Callaghan JJ, Brand RA, Pedersen DR. Hip arthrodesis: A long-term follow-up. J Bone Joint Surg Am. 1985;97:1328-35.

20. Mowery CA, Houkom JA, Roach JW, et al. A simple method of hip arthrodesis. J Pediatr Orthop. 1986;6:7-10.

21. Hoekman P, Idé G, Kassoumou AS, et al. Hip arthrodesis with the anterolateral plate: An innovating technique for an orphaned procedure. PloS One. 2014;9(1):e85868.

22. Mahran M, Omar UF. Hip arthrodesis for arthritic hip in children and young adults. Al-Azha Assiut Med J. 2015;13(4):38-42

23. Vicente JR, Ulhoa CA, Leonhardt AF, et al. Hip arthrodesis: minimum 20-year follow-up retrospective study. Act Orthop Bras. 2011;19(5):286-88

24. Benaroch TE, Richards BS, Haideri N, et al. Intermediate follow-up of a simple method of hip arthrodesis in adolescent patients. J Pediatr Orthop. 1996;16:30-36.

25. Roberts CS, Fetto JF. Functional outcomes of the hip fusion in the young patient: Follow-up study of 10 patients. J Arthrop. 1990;5:89-96.

26. Karol LA, Halliday SE, Gourineni P. Gait and function after intra-articular arthrodesis of the hip in adolescents. J Bone Joint Surg Am. 2000;82:561-69.

27. Schafroth MU, Blokzijl RJ, Haverkamp D, et al. The long-term fate of the hip arthrodesis: Does it remain a valid procedure for the selected cases in the 21 st century? Int Orthop 2010;34(6):805-10

28. Tavares JO, Frankovitch KF. Hip arthrodesis using the AO modular external fixator. J Pediatr Orthop. 1998;18:651-56.

29. The jamovi project (2020). jamovi (Version 1.2) [Computer Software]. Retrieved from: https:// jamovi.org.

30. Banskota AK, Shrestha SP, Banskota B, et al. Hip arthrodesis in children: A review of 28 patients. Indian J Orthop. 2009;43(4):383-88.

31. Saha D, Gard S, Fatone $S$, et al. The effect of trunk-flexed posture on balance and metabolic energy expenditure during standing. Spine. 2007;32(15):1605-11.

32. Matta JM, Siebenrock KA, Gautier E, et al. Hip fusion through an anterior approach with the use of a ventral plate. Clin Orthop. 1997;337:129-78.

33. Brien WW, Golz RJ, Kuschner SH, et al. Hip joint arthrodesis utilizing anterior compression plate fixation. J Arthrop. 1994;9(2):171-76.

34. Duncan CP, Spangehl M, Beauchamp C, et al. Hip arthrodesis: An important option for advanced disease in the young adult. Can J Surg. 1995;38:S39-45

35. Scher DM, Jeong GK, Grant AD, et al. Hip arthrodesis in adolescents using external fixation. J Pediatr Orthop. 2001;21(2):194-97.

36. Endo N, Takahashi HE, Toyama $\mathrm{H}$, et al. Arthrodesis of the hip joint using an external fixator. J Orthop Sci. 1999;4:343-46.

37. Wagner M, Wagner H. Hip arthrodesis using the cobra plate. Indications, technique outcome. Der Orthopäde. 1996;25(2):129-39.

38. Klemme WR, Preston J, Skinner R. Results of hip arthrodesis in adolescents by using the cobra-head plate for internal fixation. J Pediatr Orthop. 1998;18(5):648-50.

39. Shinar A, Harris W. Cemented total hip arthroplasty following previous femoral osteotomy. J Arthop. 1998;13(3):243-53.

40. Boos N, Krushell R, Ganz R, et al. Total hip arthroplasty after femoral osteotomy. J Bone Joint Surg Br. 1997;79(2):247-53.

41. Juaregui JJ, Kim JK, Shield WP, et al. Hip fusion takedown to a total hip arthroplasty - is it worth it? A systematic review. Int Orthop. 2017;41:1535-42.

42. Flecher $\mathrm{X}$, Ollivier M, Maman $\mathrm{P}$, et al. Long-term results of custom cementless-stem total hip arthroplasty performed in hip fusion. Int Orthop. 2018;42:1259-64. 